\title{
Decreased expression of microRNA-214 contributes to imatinib mesylate resistance of chronic myeloid leukemia patients by upregulating ABCB1 gene expression
}

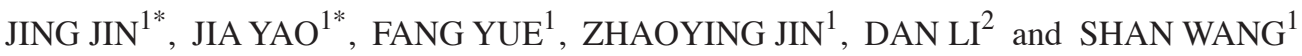 \\ ${ }^{1}$ Department of Pharmacy, Jining No. 1 People's Hospital, Jining, Shandong 272011; \\ ${ }^{2}$ Department of Pharmacy, Qilu Medical University, Zibo, Shandong 255213, P.R. China
}

Received January 18, 2018; Accepted June 1, 2018

DOI: $10.3892 /$ etm.2018.6404

\begin{abstract}
The aim of the present study was to determine the expression of adenosine triphosphate binding cassette subfamily B member 1 (ABCB1) gene and its protein P-glycoprotein (PGP) in bone marrow mononuclear cells from chronic myeloid leukemia (CML) patients with imatinib mesylate (IM) resistance, or IM-resistant CML K562 cells. In addition, the molecular mechanism of action of microRNA (miR)-214 on ABCB1 in IM resistance was investigated. A total of $26 \mathrm{CML}$ patients with IM resistance were included in the present study. In addition, $31 \mathrm{CML}$ patients who did not have IM resistance were included as the control group. Bone marrow was collected from all subjects. The K562R cell line, which is a K562 cell line with IM resistance, was used for cellular studies. Reverse transcription-quantitative polymerase chain reaction was used to determine the expression of ABCB1 mRNA and miR-214 in cells. Western blotting was employed to determine the expression of PGP. Dual luciferase reporter assay was carried out to identify interactions between ABCB1 mRNA and miR-214. MTT assay was used to determine the survival rate of cells. ABCB1 mRNA and PGP expression was upregulated in bone marrow mononuclear cells from $\mathrm{CML}$ patients with IM resistance. K562R cells had higher ABCB1 and PGP expression than K562 cells, potentially due to their different sensitivity to IM. Expression miR-214 was decreased in bone marrow mononuclear cells from patients with IM resistance and K562R cells. Notably, miR-214 was able to bind with the 3'-untranslated region, seed region of ABCB1 mRNA to regulate its expression. In addition, elevated expression of
\end{abstract}

Correspondence to: Dr Shan Wang, Department of Pharmacy, Jining No. 1 People's Hospital, 6 Jiankang Road, Jining, Shandong 272011, P.R. China

E-mail: wangshan897@126.com

*Contributed equally

Key words: imatinib mesylate, drug resistance, microRNA-214, P-glycoprotein, adenosine triphosphate binding cassette subfamily B member 1 gene
miR-214 restored IM sensitivity to K562R cells potentially by affecting ABCB1 expression. The present study demonstrated that upregulated expression of ABCB1 mRNA and PGP in bone marrow mononuclear cells from CML patients with IM resistance may be associated with the downregulation of miR-214. In addition, miR-214 may participate in the IM resistance of CML patients by regulating $\mathrm{ABCB} 1$ expression.

\section{Introduction}

Chronic myeloid leukemia (CML) is a malignant disease in which hematopoietic stem cells proliferate continuously, and it is the first tumor that is confirmed to be related to chromosome aberration (1). Epidemiology shows that the incidence of CML is about 1-2 cases/100,000 people, and most patients of CML are elderly people (median age on diagnosis, 65 years) (2). The prevalence of CML in males is higher than that in females, but the overall survival rate for females is higher than that for males (3). The incidence of CML in China is 0.36 case $/ 100,000$ people (4).

Imatinib mesylate (IM) is among the first generation of tyrosine kinase inhibitors (TKIs) that are authorized by the Food and Drug Administration of the USA in the treatment of chronic myelogenous leukemia in the chronic phase (CML-CP) (5). With the use of IM, CML-CP patients have achieved a survival rate longer than 5 years and it is predicted that their life span is close to or equivalent to that of non-leukemia patients $(2,6-8)$. In the course of long-term follow-up of CML, some patients are found to be resistant to IM (9). The incidence of drug resistance in each year of the first 3 years of treatment is $2-4 \%$ for CML-CP patients, and the drug resistance rate is gradually increasing with the prolongation of drug use $(10,11)$.

The mechanism of IM drug resistance is very complex, and the expression of multidrug transporters has attracted much attention $(12,13)$. The most intensively studied mechanism is multidrug resistance (MDR) mediated by P-glycoprotein (PGP) and multidrug resistance-associated protein-1 (MRP1) (14-16). PGP is encoded by multidrug resistance gene (adenosine triphosphate binding cassette subfamily B member 1 (ABCB1), also known as MDR1), and involved in drug absorption, distribution, metabolism, and excretion (17). 
Therefore, the regulation of $\mathrm{ABCB} 1$ has become an important research direction for IM resistance therapy.

microRNA (miRNA or miR) molecules are small-molecule non-encoding RNA molecules that widely exist in eukaryotic cells, and they regulate protein expression at mRNA level (18-20). Studies show that miRNA plays important biological roles in imatinib resistance $(21,22)$. This process is also accompanied by alterations in the expression of multiple miRNA and proteins. The microRNA that is upstream of $\mathrm{ABCB} 1$ and regulates $\mathrm{ABCB} 1$ expression in $\mathrm{CML}$ has not been reported yet. In the present study, we determine the expression of ABCB1 and its upstream miRNA, and try to understand the mechanism of regulation between them.

\section{Materials and methods}

Patients. A total of $26 \mathrm{CML}$ patients with IM resistance were included into the present study between December 2013 and June 2017. In addition, 31 CML patients who do not have IM resistance were included into control group (Table I). Bone marrow was collected from all subjects. Among the 26 patients with IM resistance, 15 were males and 11 were females (age range, 17-66 years; median age, 52.6 years). In addition, 20 patients with IM resistance were in chronic phase, while 6 patients were in accelerated phase. Among the 31 patients in control group, 19 were males and 12 were females (age range, 15-69 years; median age, 53.5 years). Moreover, 28 patients in control group were in chronic phase, while 3 patients in control group were in accelerated phase. All patients received treatments for IM. The standard for the diagnosis of IM resistance in CML patients includes: i) no hematologic remission was achieved within 3 months; ii) no complete hematologic remission or cytogenetic remission was achieved within 6 months; iii) failure to achieve major cytogenetic remission within 12 months or complete cytogenetic remission within 18 months and iv) loss of prior hematologic or cytogenetic remission, or the emergence of Abl kinase point mutations with high IM resistance (23). All procedures were approved by the Ethics Committee of Jining No. 1 People's Hospital (Shandong, China). Written informed consents were obtained from all patients or their families.

Cells. K562 cell line was a kind of CML cell line, while K562R cell line was K562 cell line with IM resistance. Both types of cell lines were originally purchased from American Type Culture Collection (ATCC, Manassas, VA, USA) and kept at our lab. One day before transfection, K562R cells in log-phase growth were seeded into 24 -well plates $\left(3 \times 10^{5}\right.$ in each well) containing antibiotics-free F12/DMEM medium supplemented with $10 \%$ fetal bovine serum and cultured at $37^{\circ} \mathrm{C}$ and $5 \% \mathrm{CO}_{2}$. When reaching $70 \%$ confluency, transfection began. In the first vial, $1 \mu \mathrm{l}$ agomiR-214 (20 pmol $/ \mu \mathrm{l}$; miR-214 mimics group; Sangon Biotech Co., Ltd., Shanghai, China) was mixed with $50 \mu$ l Opti Mem medium (Thermo Fisher Scientific, Inc., Waltham, MA, USA). Here, agomiR-214 was an artificially synthesized modified double-chain miR-214 with the same function with mature form of miR-214 (24). In the second vial, $1 \mu$ l Lipofectamine 2000 (Thermo Fisher Scientific, Inc.) was mixed with $50 \mu 1$ Opti Memi medium. After standing still for $5 \mathrm{~min}$, the two vials were combined before incubation at room temperature for $20 \mathrm{~min}$. Then, the mixtures were added onto cells in respective groups. Six hour later, the medium was replaced with F12/DMEM medium containing $10 \%$ fetal bovine serum. After cultivation at $37^{\circ} \mathrm{C}$ and $5 \% \mathrm{CO}_{2}$ for $48 \mathrm{~h}$, the cells were collected for further assays.

To obtain mononuclear cells in bone marrow, bone marrow samples were first mixed with equal amount of phosphate-buffered saline (v/v, 1:1). Then, the mixture was added gently onto Ficoll-Paque Premium lymphocyte separation medium (GE Healthcare, Chicago, IL, USA) with a ratio of 2:1 before centrifugation at 2,000 rpm for $20 \mathrm{~min}$. After centrifugation, the middle layer was aspirated and thoroughly mixed with 5 volumes of phosphate-buffered saline before centrifugation at 1,500 rpm for $10 \mathrm{~min}$. After discarding supernatant, 5 volumes of phosphate-buffered saline were added again followed by thorough mixing. After centrifugation at 1,500 rpm for $10 \mathrm{~min}$, the supernatant was discarded again. The cells that were attached on the bottom were mononuclear cells in bone marrow.

Reverse transcription-quantitative polymerase chain reaction $(R T-q P C R)$. Total RNA was extract from cells using TRIzol reagent following the manufacturer's manual (Yeasen, Shanghai, China). Then, total RNA was extracted using phenol chloroform method. The concentration and quality of RNA was measured using ultraviolet spectrophotometry (Nanodrop ND2000; Thermo Fisher Scientific, Inc.). Then, cDNA was obtained by reverse transcription from $1 \mu \mathrm{g}$ RNA and stored at $-20^{\circ} \mathrm{C}$. Reverse transcription of mRNA was performed using TIANScript II cDNA First Strand Synthesis kit (Tiangen Biotech Co., Ltd., Beijing, China), and reverse transcription of miRNA was carried out using miRcute miRNA cDNA First Strand Synthesis kit (Tiangen Biotech Co., Ltd.).

SuperReal PreMix (SYBR-Green) RT-qPCR kit (Tiangen Biotech Co., Ltd.) was used to detect mRNA expression of Abcbla, using GAPDH as internal reference. The sequences of Abcbla were 5'-TGGGGCTGGACTTCCTCTCATGATGC-3' (sense) and 5'-GCAGCAACCAGCACCCCAGCACCAAT-3' (anti-sense). The sequences of GAPDH were 5'-AGAAGG CTGGGGCTCATTTG-3' (sense) and 5'-GGAACGCTTCAC GAATTTG-3' (anti-sense). The reaction system (25 $\mu \mathrm{l})$ was composed of $12.5 \mu \mathrm{l}$ SYBR Premix EXTaq, $0.5 \mu 1$ upstream primer, $0.5 \mu \mathrm{l}$ downstream primer, $1 \mu \mathrm{l} \mathrm{cDNA}$ and $10.5 \mu \mathrm{l}$ $\mathrm{ddH}_{2} \mathrm{O}$. PCR condition was: Initial denaturation at $95^{\circ} \mathrm{C}$ for $3 \mathrm{~min} ; 40$ cycles of denaturation at $95^{\circ} \mathrm{C}$ for $10 \mathrm{sec}$, annealing at $60^{\circ} \mathrm{C}$ for $30 \mathrm{sec}$, and elongation at $72^{\circ} \mathrm{C}$ for $20 \mathrm{sec}$ (iQ5; Bio-Rad Laboratories, Inc., Hercules, CA, USA). The $2^{-\Delta \Delta \mathrm{Cq}}$ method (25) was used to calculate the relative expression of Abcbla mRNA against GAPDH. Each sample was tested in triplicate.

The expression of miR-214 was determined by miRcute miRNA RT-PCR kit (Tiangen Biotech Co., Ltd.), using U6 as internal reference. The sequences of miR-214 primers were 5'-AGCATAATACAGCAGGCACAGAC-3' (upstream) and 5'-AAAGGTTGTTCTCCACTCTCTCAC-3' (downstream). The sequences of U6 were 5'-ATTGGAACGATACAGAGA AGATT-3' (upstream) and 5'-GGAACGCTTCACGAA TTTG-3' (downstream). The reaction system (20 $\mu \mathrm{l})$ contained $10 \mu \mathrm{l}$ RT-qPCR-Mix, $0.5 \mu 1$ upstream primer, $0.5 \mu 1$ downstream universal primer, $2 \mu \mathrm{l}$ cDNA and $7 \mu \mathrm{lddH_{2 }} \mathrm{O}$. The 
reaction protocol was: Initial denaturation at $95^{\circ} \mathrm{C}$ for $3 \mathrm{~min}$; 40 cycles of denaturation at $95^{\circ} \mathrm{C}$ for $12 \mathrm{sec}$, annealing at $62^{\circ} \mathrm{C}$ for $40 \mathrm{sec}$ and $72^{\circ} \mathrm{C}$ for $20 \mathrm{sec}$ (iQ5; Bio-Rad Laboratories, Inc.). The $2^{-\triangle \Delta C q}$ method (25) was used to calculate the relative expression of miR-214 against U6. Each sample was tested in triplicate.

Western blot analysis. Cells $\left(1 \times 10^{6}\right)$ in each group were collected and precooled Radio-Immunoprecipitation Assay (RIPA) lysis buffer $(1,000 \mu \mathrm{l} ; 50 \mathrm{mM}$ Tris-base, $1 \mathrm{mM}$ EDTA, $150 \mathrm{mM} \mathrm{NaCl}, 0.1 \%$ sodium dodecyl sulfate, $1 \%$ TritonX-100, $1 \%$ sodium deoxycholate; Beyotime Institute of Biotechnology, Shanghai, China) was added to the cells. After lysis for $40 \mathrm{~min}$ on ice, the mixture was centrifuged at $12,000 \mathrm{rpm}$ and $4^{\circ} \mathrm{C}$ for $10 \mathrm{~min}$. The supernatant was used to determine protein concentration by bicinchoninic acid (BCA) protein concentration determination kit (RTP7102, Real-Times Biotechnology Co., Ltd., Beijing, China). Protein samples were then mixed with $2 x$ sodium dodecyl sulfate loading buffer before denaturation in boiling water bath for $10 \mathrm{~min}$. Afterwards, the samples $(20 \mu \mathrm{g})$ were subjected to $10 \%$ sodium dodecyl sulfate-polyacrylamide gel electrophoresis (100 V). The resolved proteins were transferred to polyvinylidene difluoride membranes on ice $(100 \mathrm{~V}, 2 \mathrm{~h})$ and blocked with $5 \%$ skimmed milk at room temperature for $1 \mathrm{~h}$. Then, the membranes were incubated with rabbit anti-human PGP (1:3,000; Abcam, Cambridge, UK) and rabbit anti-human $\beta$-actin (1:5,000; Abcam) polyclonal primary antibodies at $4^{\circ} \mathrm{C}$ overnight. After extensive washing with phosphate-buffered saline with Tween 20 for 5 times of $5 \mathrm{~min}$, the membranes were incubated with goat anti-rabbit horseradish peroxidase-conjugated secondary antibodies (1:3,000; Abcam) for $1 \mathrm{~h}$ at room temperature before washing with phosphate-buffered saline with Tween 20 for 5 times of $5 \mathrm{~min}$. Then, the membrane was developed with enhanced chemiluminescence detection kit (Abcam) for imaging. Image Lab v3.0 software (Bio-Rad Laboratories, Inc.) was used to acquire and analyze imaging signals. The relative content of target protein was expressed against $\beta$-actin.

Bioinformatics. Bioinformatics prediction is a powerful tool for the study of the functions of miRNAs. To understand the regulatory mechanism of ABCB1, we used miRanda (http://www.microrna.org/microrna/home.do), TargetScan (http://www.targetscan.org), PiTa (http://genie. weizmann.ac.il/pubs/mir07/mir07_data.html), RNAhybrid (http://bibiserv.techfak.uni-bielefeld.de/rnahybrid/) and PICTA (http://pictar.mdc-berlin.de/) to predict miRNA molecules that might regulate $\mathrm{ABCB} 1$, and found that miR-214 was able to potentially regulate ABCB1 (Fig. 1).

Dual luciferase reporter assay. According to bioinformatics results, wild-type (WT) and mutant seed regions of miR-214 in the 3'-UTR (150 bp upstream and downstream of CCUGCUG) of ABCB1 gene were chemically synthesized in vitro, added with Spe-1 and HindIII restriction sites, and then cloned into pMIR-REPORT luciferase reporter plasmids. Plasmids $(0.8 \mu \mathrm{g})$ with WT or mutant 3'-UTR DNA sequences were co-transfected with agomiR-214 (100 nM; Sangon Biotech Co., Ltd.) into 293T cells. After cultivation for $24 \mathrm{~h}$, the cells were lysed using dual luciferase reporter assay
Table I. Clinical characteristics of CML and IM-resistant patients.

\begin{tabular}{lcc}
\hline Characteristics & $\begin{array}{c}\text { CML } \\
\text { patients }\end{array}$ & $\begin{array}{c}\text { IM-resistant } \\
\text { patients }\end{array}$ \\
\hline Sex (n) & & \\
Male & 19 & 15 \\
Female & 12 & 11 \\
Age range (years) & $15-69$ & $17-66$ \\
Median age (years) & 53.5 & 52.6 \\
Treatment duration (months) & $1-2$ & $3-18$ \\
White blood cell count (x10 $/ 1)$ & $78 \pm 33$ & $108 \pm 56$ \\
\hline
\end{tabular}

CML, chronic myeloid leukemia; IM, imatinib mesylate.

kit (Promega Corporation, Madison, WI, USA) according to the manufacturer's manual, and luminescence intensity was measured using GloMax 20/20 luminometer (Promega Corporation). Using Renilla luminescence activity as internal reference, the luminescence values of each group of cells were measured.

MTT assay. After transfection, cells were seeded into 96-well plates at a density of $2 \times 10^{3}$ cells per well and cultured in the presence of $1 \mu \mathrm{M}$ IM. Each condition was tested in triplicate wells according to a previously published method (26). At 24, 48, and 72 h, $20 \mu$ l MTT (5 g/l, JRDC000003; JRDUN Biotechnology, Shanghai, China) was added into each well. On the last day, DMSO (150 $\mu \mathrm{l}$ per well) was added to dissolve purple crystals after incubation at $37^{\circ} \mathrm{C}$ for $4 \mathrm{~h}$. Then, absorbance of each well was measured at $490 \mathrm{~nm}$ with a microplate reader (Bio-Rad Laboratories, Inc.). Cell survival curves were plotted.

Statistical analysis. The results were analyzed using SPSS v.18.0 statistical software (SPSS, Inc., Chicago, IL, USA). The data were expressed as the mean \pm standard deviation. Data were tested for normality. Multigroup measurement data were analyzed using one-way analysis of variance. In case of homogeneity of variance, the Least Significant Difference and Student-Newman-Keuls post hoc methods were used; in case of heterogeneity of variance, Tamhane's T2 or Dunnett's T3 post hoc methods were used. $\mathrm{P}<0.05$ was considered to indicate a statistically significant difference.

\section{Results}

ABCB1 $\mathrm{mRNA}$ and PGP expression is up-regulated in bone marrow mononuclear cells from CML patients with IM resistance. To measure the expression of $\mathrm{ABCB} 1 \mathrm{mRNA}$ and its protein PGP in bone marrow mononuclear cells, RT-qPCR and western blotting were performed. The data showed that the levels of ABCB1 mRNA and PGP in mononuclear cells from patients with IM resistance were significantly higher than those from patients without IM resistance $(\mathrm{P}<0.05$; Fig. 2A and B). The result suggests that ABCB1 mRNA and PGP expression is up-regulated in bone marrow mononuclear cells from CML patients with IM resistance. 


\section{3' ugACGGAC-AGACACGGACGACa 5' hsa-miR-214 | |:|| :|| |||||||}

571:5' ucUUCUUgGaCUUGAUCCUGCUGa 3' ABCB1

Figure 1. Direct interaction between miRNA-214 and ABCB1. Bioinformatics prediction was employed to understand the regulatory mechanism of $\mathrm{ABCB} 1$, using miRanda, TargetScan, PiTa, RNAhybrid and PICTA databases in order to predict the miRNA molecules that may regulate ABCB1. miR-214 was revealed to be able to potentially regulate $\mathrm{ABCB} 1$. miR/miRNA, microRNA; ABCB1, adenosine triphosphate binding cassette subfamily B member 1.
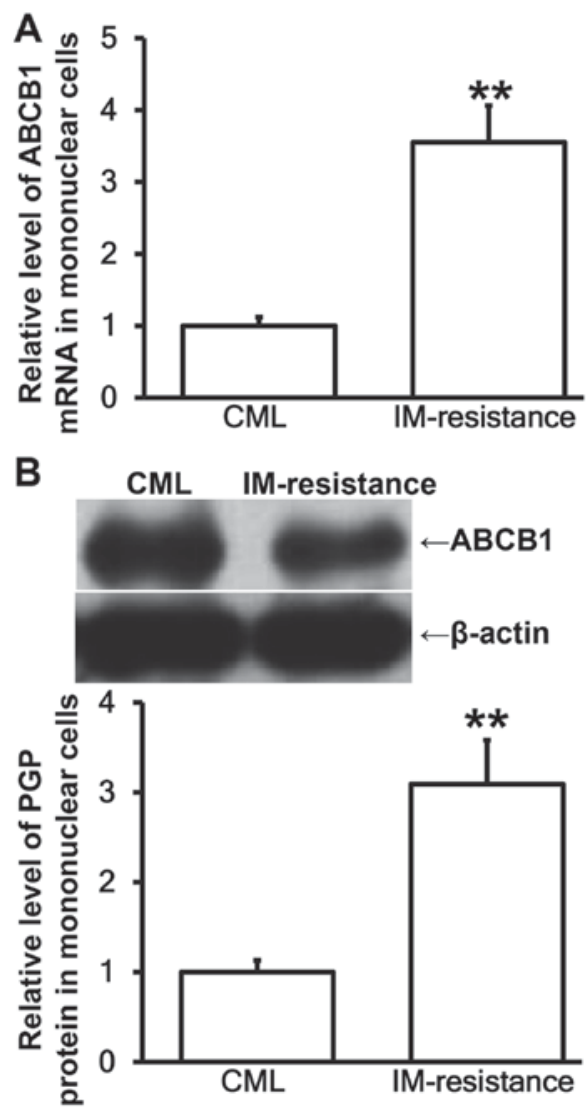

Figure 2. Expression of (A) ABCB1 mRNA and (B) PGP in mononuclear cells from CML patients without or with IM resistance. Reverse transcription-quantitative polymerase chain reaction was used to measure the expression of mRNA, while western blotting was used to determine protein expression. ${ }^{* *} \mathrm{P}<0.01$ vs. CML group. $\mathrm{ABCB} 1$, adenosine triphosphate binding cassette subfamily B member 1; PGP, P-glycoprotein; CML, chronic myeloid leukemia; IM, imatinib mesylate.

$K 562 R$ cells have higher $A B C B 1$ and PGP expression than K562 cells, probably due to their different sensitivity to IM. To determine the expression of $\mathrm{ABCB} 1 \mathrm{mRNA}$ and its protein PGP in K562 and K562R cells, RT-qPCR and western blotting were employed. The data showed that the levels of ABCB1 mRNA and PGP in K562R cells were significantly increased than those in K562 cells $(\mathrm{P}<0.05$; Fig. 3A and B). The result indicates that K562R cells have higher ABCB1 and PGP expression than K562 cells, probably due to their different sensitivity to IM.

Expression miR-214 is decreased in bone marrow mononuclear cells from patients with IM resistance and K562R cells. To test the levels of miR-214 in bone marrow mononuclear
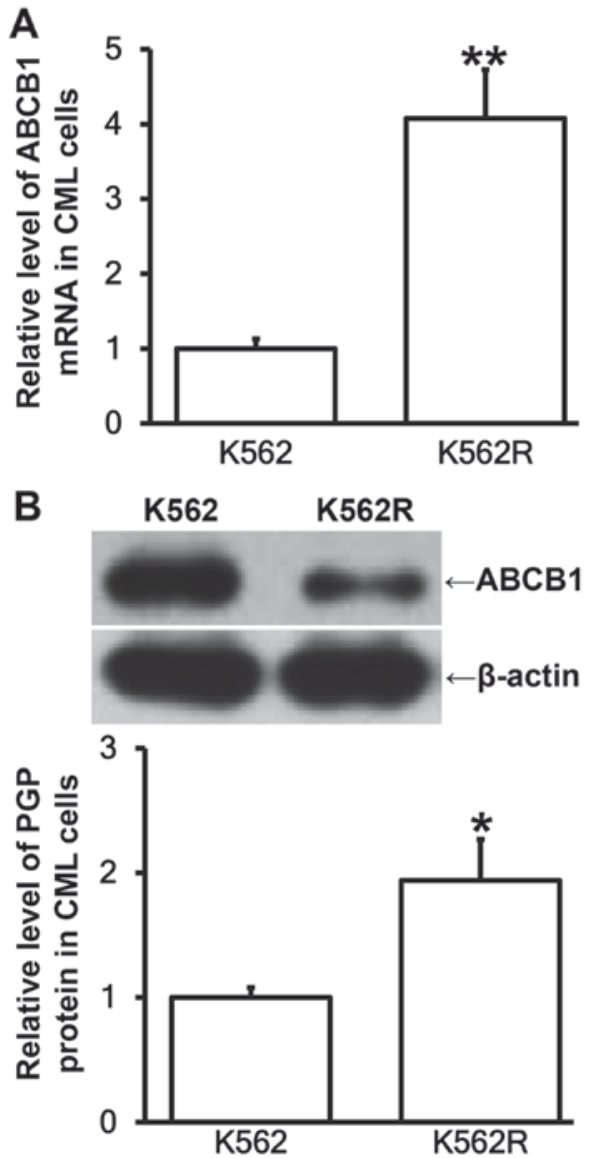

Figure 3. Expression of (A) ABCB1 mRNA and (B) PGP in CML cells. The K562 cell line is a CML cell line without IM resistance, while the K562R cell line is a K562 cell line with IM resistance. Reverse transcription-quantitative polymerase chain reaction was used to measure the expression of mRNA, while western blotting was used to determine protein expression. " $\mathrm{P}<0.05$ and ${ }^{* *} \mathrm{P}<0.01$ vs. $\mathrm{K} 562$ group. $\mathrm{ABCB} 1$, adenosine triphosphate binding cassette subfamily B member 1; PGP, P-glycoprotein; CML, chronic myeloid leukemia; IM, imatinib mesylate.

cells and K562R cells, RT-qPCR was carried out. The data showed that miR-214 levels in bone marrow mononuclear cells from patients with IM resistance were significantly lower than that from patients without IM resistance $(\mathrm{P}<0.05$; Fig. 4A). Similarly, miR-214 expression in K562R cells was significantly decreased than that in K562 cells ( $\mathrm{P}<0.05$; Fig. 4B). The results suggest that the expression miR-214 is decreased in bone marrow mononuclear cells from patients with IM resistance and K562R cells.

miR-214 can bind with the 3'-UTR seed region of ABCBI $m R N A$ to regulate its expression. To identify the interaction between miR-214 and the 3'-UTR of ABCB1 mRNA, dual luciferase reporter assay was performed. The luminescence value of cells co-transfected with agomiR-214 and pMIR-REPORT-WT luciferase reporter plasmids was significantly lower than that in negative control group $(\mathrm{P}<0.05)$. By contrast, the luminescence value of cells co-transfected with agomiR-214 and pMIR-REPORT-mutant luciferase reporter plasmids was not significantly different from that in negative control group ( $>0.05$; Fig. 5 ). The result suggests that miR-214 can bind with the 3'-UTR seed region of ABCB1 mRNA to regulate its expression. 

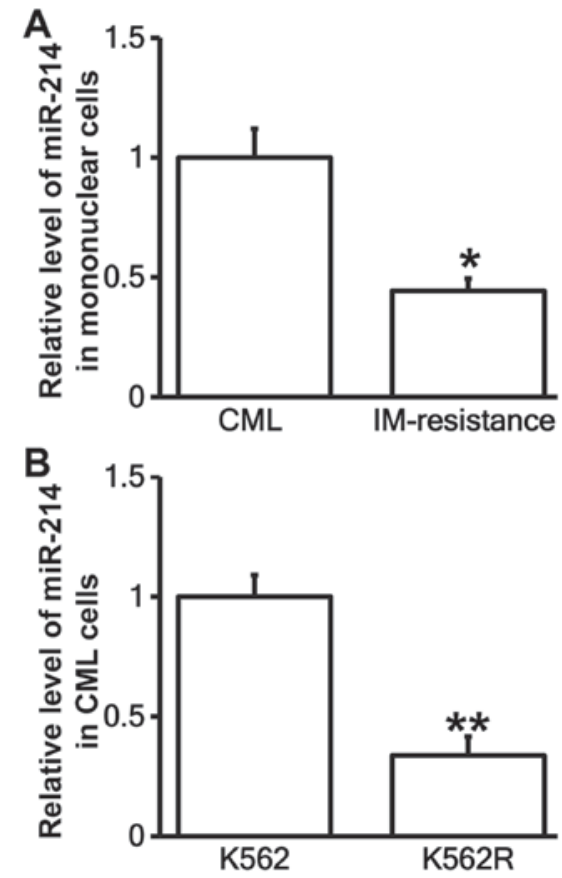

Figure 4. Expression of miR-214 in (A) mononuclear cells from CML patients with or without IM resistance and (B) CML K562 or K562R cells. Reverse transcription-quantitative polymerase chain reaction was used to measure the expression of miR-214. ${ }^{*} \mathrm{P}<0.05$ and ${ }^{* *} \mathrm{P}<0.01$ vs. (A) CML group and (B) K562 group, respectively. miR, microRNA; CML, chronic myeloid leukemia; IM, imatinib mesylate.

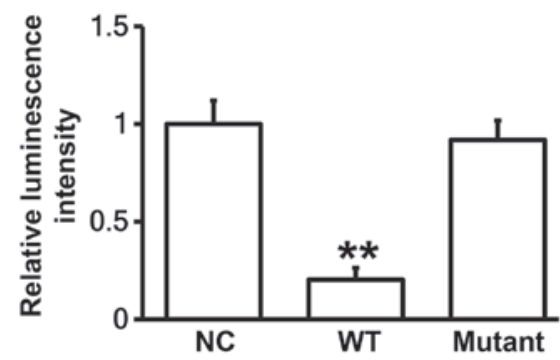

Figure 5. Identification of the interaction between miR-214 and ABCB1 using dual luciferase reporter assay. Plasmids $(0.8 \mu \mathrm{g})$ with WT or mutant 3'-untranslated region DNA sequences were co-transfected with agomiR-214 into $293 \mathrm{~T}$ cells. Following cultivation for $24 \mathrm{~h}$, the cells were lysed using dual luciferase reporter assay kit, and luminescence intensity was measured using GloMax 20/20 luminometer. Using Renilla luminescence activity as the internal reference, the luminescence values of each group of cells were measured. ${ }^{* *} \mathrm{P}<0.01$ vs. NC group. miR, microRNA; ABCB1, adenosine triphosphate binding cassette subfamily B member 1; WT, wild-type; NC, negative control.

Elevated expression of $m i R-214$ restores IM-sensitivity to $K 562 R$ cells possibly by affecting ABCBI expression. To test how miR-214 affects the expression of ABCB1 mRNA and PGP protein, we used RT-qPCR, western blotting and MTT assay. The data showed that expression of miR-214 in K562R cells after transfection with agomiR-214 was significantly enhanced $(\mathrm{P}<0.05$; Fig. 6A). In addition, the expression of ABCB1 mRNA in K562R cells transfected with agomiR-214 was significantly lower than that in K562R cells transfected with negative control $(\mathrm{P}<0.05$; Fig. 6B). Similarly, PGP expression in K562R cells transfected with agomiR-214 was significantly reduced than that in K562R cells transfected with negative control ( $\mathrm{P}<0.05$; Fig. 6C). Of note, MTT assay showed that the survival rate of K562R cells transfected with agomiR-214 was significantly reduced than those of K562R cells transfected with negative control or K562 cells at 24, 48 and $72 \mathrm{~h}$ in the presence of IM ( $\mathrm{P}<0.05$ for all points; Fig. 6D). The results indicate that elevated expression of miR-214 restores IM sensitivity to K562R cells possibly by affecting ABCB1 expression.

\section{Discussion}

CML is the first tumor that has targeted therapeutics drugs designed according to its disease-causing gene types (2). Discontinuation of IM treatment results in high frequency of disease recurrence, indicating that only a small proportion of patients may receive curative or prolonged remission after treatment $(27,28)$. IM resistance has become an important issue in the treatment of CML. Studies show that overexpression of multidrug transporter and drug target enzyme may be involved in IM resistance of CML (29-31). Multidrug transporters, such as PGP, MRPS, LRP and BCRP, can increase intracellular drug efflux or vesicle isolation, resulting in decreased intracellular drug concentration or altered drug distribution. The best studied is MDR mediated by P-GP/MDRI and MRPI. It is first discovered in colchicine-resistant Chinese hamster ovary cells (32), and later found in all tissues of the organism (33). MDR prevents the body from absorbing harmful substances, mediates the output of substances, protects the brain and testis (34). It is reported that PGP expressed by ABCB1 gene in human body is closely related to drug distribution and translocation (34). PGP utilizes ATP in the organism to transport exogenous drugs and toxins outside the cells, reduces the concentration of intracellular drugs and toxins, decreases effect of drug treatment, and produces drug resistance (35). In the present study, we discover that expression of ABCB1 mRNA and PGP in mononuclear cells from CML patients with IM resistance is up-regulated, and similar trend is also observed for K562R that has IM resistance. This suggests that ABCB1 gene and its encoded protein play regulatory roles in IM resistance.

Our further study is then focused on the upstream miRNA that may regulate $\mathrm{ABCB} 1$ expression. It is reported that miRNA molecules cut mRNA and inhibits its translation to achieve a negative feedback regulation $(36,37)$. miRNA molecules are important regulators in development, normal physiology, and diseases. Moreover, some miRNA molecules have become biomarkers for diseases $(38,39)$. Using bioinformatics, we have discovered that miR-214 is an upstream regulator gene of $\mathrm{ABCB} 1$. It is reported that miR-214 can be used as a predictive factor for the diagnosis of gastric cancer, and it can also affect the proliferation and invasion of tumor cells (40). In addition, miR-214 can affect the proliferation and invasion of breast cancer through P53 (41). miRNA-214 can also inhibit bladder cancer growth by targeting PDRG1 gene (42). Moreover, Wan et al (43) report that miR-214 has a protective role in the post treatment for myocardial ischemia, and Izawa et al (44) discover that miR-214 effectively alleviates thioacetamide-induced cirrhosis and may have an anti-fibrotic effect. In the present study, we find that expression of miR-214 is reduced in both mononuclear cells from IM-resistant CML patients and K562R cells. Furthermore, dual luciferase 
A
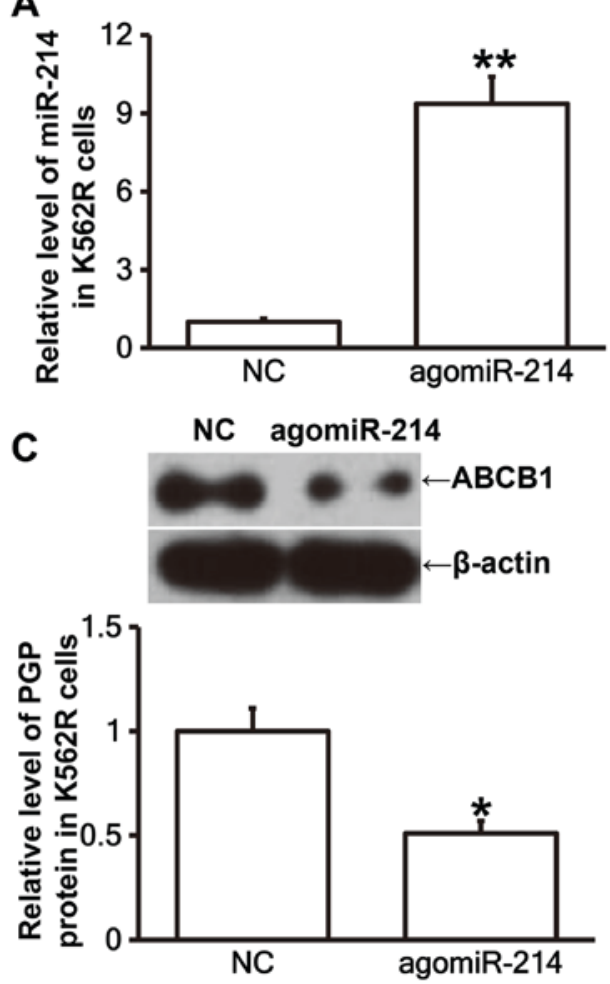
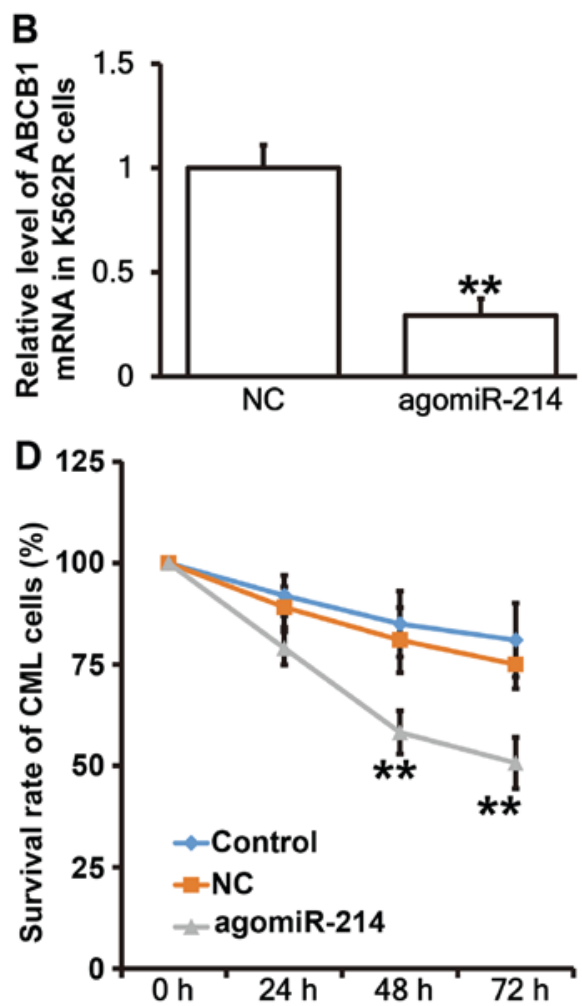

Figure 6. Effect of miR-214 expression on the expression of ABCB1 mRNA and PGP protein, as well as the survival of CML cells. (A) Expression of miR-214 in K562R cells transfected with NC or agomiR-214. Expression of (B) ABCB1 mRNA and (C) PGP in K562R cells transfected with NC or agomiR-214. (D) Survival rate of K562 cells (control), and K562R cells transfected with NC or agomiR-214 in the presence of IM (1 $\mu$ M). Reverse transcription-quantitative polymerase chain reaction was employed to measure the expression of miR-214 and ABCB1 mRNA, western blotting was used to determine PGP expression, and MTT assay was performed to determine cell survival rate. ${ }^{*} \mathrm{P}<0.05$ and ${ }^{* *} \mathrm{P}<0.01$ vs. NC group. miR, microRNA; ABCB1, adenosine triphosphate binding cassette subfamily B member 1; PGP, P-glycoprotein; CML, chronic myeloid leukemia; NC, negative control; IM, imatinib mesylate.

reporter assay demonstrates that miR-214 directly binds with the 3'-UTR seeding region of ABCB1 mRNA and regulates its expression. Then, we have transfected agomiR-214 into K562R cells to up-regulate the expression of miR-214 in these cells. After culturing the cells in IM medium, we find that the survival rate of K562R cells transfected with agomiR-214 is reduced in the presence of $\mathrm{IM}$, suggesting that the sensitivity of K562R cells to IM is partially restored by overexpression of miR-214. The limitations of the study include low sequence homology between miRNA-214 and the ABCB1 gene and relatively small sample numbers in some experiments. We will improve this in future studies.

In conclusion, the present study demonstrates that miR-214 alters the expression of PGP by targeting ABCB1, and elevates IM resistance of CML cells. It plays an important biological role in IM resistance of CML patients.

\section{Acknowledgements}

The authors would like to thank the research teams at the Department of Pharmacy, Jining No. 1 People's Hospital (Shandong, China), and the Department of Pharmacy, Qilu Medical University (Shandong, China) for their assistance during the present study.

\section{Funding}

No funding was received.

\section{Availability of data and materials}

The datasets used and/or analyzed during the present study are available from the corresponding author on reasonable request.

\section{Authors' contributions}

JJ and JY collaborated on the design of the present study, performed the experiments, and analyzed the data. FY, ZJ and DL contributed to the literature review, and assisted with the experimental design and completion. SW was responsible for experimental design, data collection and analysis, and writing the manuscript. All authors collaborated to interpret the results and develop the manuscript. The final version of the manuscript has been read and approved by all authors.

\section{Ethics approval and consent to participate}

All procedures were approved by the Ethics Committee of Jining No. 1 People's Hospital (Shandong, China). Written informed consents were obtained from all patients or their families.

\section{Consent for publication}

Written informed consent for the publication of any associated data and accompanying images were obtained from all patients, or their parents, guardians or next of kin. 


\section{Competing interests}

The authors declare that they have no competing interests.

\section{References}

1. Nowell PC: The minute chromosome (Phl) in chronic granulocytic leukemia. Blut 8: 65-66, 1962

2. Hehlmann R, Hochhaus A and Baccarani M; European LeukemiaNet: Chronic myeloid leukaemia. Lancet 370: 342-350, 2007.

3. Berger U, Maywald O, Pfirrmann M, Lahaye T, Hochhaus A, Reiter A, Hasford J, Heimpel H, Hossfeld DK, Kolb HJ, et al: Gender aspects in chronic myeloid leukemia: Long-term results from randomized studies. Leukemia 19: 984-989, 2005.

4. Wang JX, Huang XJ, Wu DP, Hu JD, Liu T, Hu Y, Meng FY, Chen XQ Hou M, Li Y, et al: Overview of chronic myelogenous leukemia and its current diagnosis and treatment patterns in 15 hospitals in China. Zhonghua Xue Ye Xue Za Zhi 30: 721-725, 2009 (In Chinese).

5. Cohen MH, Williams G, Johnson JR, Duan J, Gobburu J, Rahman A, Benson K, Leighton J, Kim SK, Wood R, et al: Approval summary for imatinib mesylate capsules in the treatment of chronic myelogenous leukemia. Clin Cancer Res 8: 935-942, 2002.

6. Eskazan AE, Ar MC and Soysal T: Critical appraisal of European LeukemiaNet (ELN) 2013 recommendations for the management of chronic myeloid leukemia: Is it early for a warning? Expert Rev Hematol 9: 919-921, 2016.

7. Höglund M, Sandin F, Hellström K, Björeman M, Björkholm M, Brune M, Dreimane A, Ekblom M, Lehmann S, Ljungman P, et al: Tyrosine kinase inhibitor usage, treatment outcome, and prognostic scores in CML: Report from the population-based Swedish CML registry. Blood 122: 1284-1292, 2013.

8. Kantarjian H, O'Brien S, Jabbour E, Garcia-Manero G, Quintas-Cardama A, Shan J, Rios MB, Ravandi F, Faderl S, Kadia T, et al: Improved survival in chronic myeloid leukemia since the introduction of imatinib therapy: A single-institution historical experience. Blood 119: 1981-1987, 2012.

9. Shah NP: Loss of response to imatinib: Mechanisms and management. Hematology Am Soc Hematol Educ Program: $183-187,2005$.

10. La Rosée P and Hochhaus A: Resistance to imatinib in chronic myelogenous leukemia: Mechanisms and clinical implications. Curr Hematol Malig Rep 3: 72-79, 2008.

11. Hochhaus A and Hughes T: Clinical resistance to imatinib: Mechanisms and implications. Hematol Oncol Clin North Am 18: 641-656, ix, 2004.

12. Vine J, Cohen SB, Ruchlemer R, Goldschmidt N, Levin M, Libster D, Gural A, Gatt ME, Lavie D, Ben-Yehuda D and Rund D: Polymorphisms in the human organic cation transporter and the multidrug resistance gene: Correlation with imatinib levels and clinical course in patients with chronic myeloid leukemia. Leuk Lymphoma 55: 2525-2531, 2014.

13. Gromicho M, Dinis J, Magalhães M, Fernandes AR, Tavares P, Laires A, Rueff J and Rodrigues AS: Development of imatinib and dasatinib resistance: Dynamics of expression of drug transporters ABCB1, ABCC1, ABCG2, MVP, and SLC22A1. Leuk Lymphoma 52: 1980-1990, 2011

14. Mlejnek P, Kosztyu P, Dolezel P, Bates SE and Ruzickova E: Reversal of ABCB1 mediated efflux by imatinib and nilotinib in cells expressing various transporter levels. Chem Biol Interact 273: 171-179, 2017.

15. Zhou ZY, Wan LL, Yang QJ, Han YL, Li D, Lu J and Guo C: Nilotinib reverses ABCB1/P-glycoprotein-mediated multidrug resistance but increases cardiotoxicity of doxorubicin in a MDR xenograft model. Toxicol Lett 259: 124-132, 2016.

16. Negi LM, Jaggi M, Joshi V, Ronodip K and Talegaonkar S: Hyaluronan coated liposomes as the intravenous platform for delivery of imatinib mesylate in MDR colon cancer. Int J Biol Macromol 73: 222-235, 2015

17. Leslie EM, Deeley RG and Cole SP: Multidrug resistance proteins: Role of P-glycoprotein, MRP1, MRP2, and BCRP (ABCG2) in tissue defense. Toxicol Appl Pharmacol 204: 216-237, 2005

18. Graziano A, Lo Monte G, Piva I, Caserta D, Karner M, Engl B and Marci R: Diagnostic findings in adenomyosis: A pictorial review on the major concerns. Eur Rev Med Pharmacol Sci 19: $1146-1154,2015$
19. Jia W, Wu Y, Zhang Q, Gao GE, Zhang C and Xiang Y: Expression profile of circulating microRNAs as a promising fingerprint for cervical cancer diagnosis and monitoring. Mol Clin Oncol 3: 851-858, 2015.

20. Jiang XI, Luo Y, Zhao S, Chen Q, Jiang C, Dai Y, Chen Y and Cao Z: Clinical significance and expression of microRNA in diabetic patients with erectile dysfunction. Exp Ther Med 10: 213-218, 2015.

21. Zhou H, Li Y, Liu B, Shan Y, Li Y, Zhao L, Su Z and Jia L: Downregulation of miR-224 and let-7i contribute to cell survival and chemoresistance in chronic myeloid leukemia cells by regulating ST3GAL IV expression. Gene 626: 106-118, 2017.

22. Liu L, Wang S, Chen R, Wu Y, Zhang B, Huang S, Zhang J, Xiao F, Wang M and Liang Y: Myc induced miR-144/451 contributes to the acquired imatinib resistance in chronic myelogenous leukemia cell K562. Biochem Biophys Res Commun 425: 368-373, 2012

23. Baccarani M, Saglio G, Goldman J, Hochhaus A, Simonsson B, Appelbaum F, Apperley J, Cervantes F, Cortes J, Deininger M, et al: Evolving concepts in the management of chronic myeloid leukemia: Recommendations from an expert panel on behalf of the European LeukemiaNet. Blood 108: 1809-1820, 2006

24. Hou J, Lin L, Zhou W, Wang Z, Ding G, Dong Q, Qin L, Wu X, Zheng Y, Yang Y, et al: Identification of miRNomes in human liver and hepatocellular carcinoma reveals miR-199a/b-3p as therapeutic target for hepatocellular carcinoma. Cancer Cell 19: 232-243, 2011.

25. Livak KJ and Schmittgen TD: Analysis of relative gene expression data using real-time quantitative PCR and the 2(-Delta Delta C(T)) method. Methods 25: 402-408, 2001.

26. Leone G, D'Alò F, Zardo G, Voso MT and Nervi C: Epigenetic treatment of myelodysplastic syndromes and acute myeloid leukemias. Curr Med Chem 15: 1274-1287, 2008.

27. Mahon FX, Réa D, Guilhot J, Guilhot F, Huguet F, Nicolini F, Legros L, Charbonnier A, Guerci A, Varet B, et al: Discontinuation of imatinib in patients with chronic myeloid leukaemia who have maintained complete molecular remission for at least 2 years: The prospective, multicentre Stop Imatinib (STIM) trial. Lancet Oncol 11: 1029-1035, 2010.

28. Cortes J, O'Brien S and Kantarjian H: Discontinuation of imatinib therapy after achieving a molecular response. Blood 104: 2204-2205, 2004.

29. D'Cunha R, Bae S, Murry DJ and An G: TKI combination therapy: Strategy to enhance dasatinib uptake by inhibiting Pgpand BCRP-mediated efflux. Biopharm Drug Dispos 37: 397-408, 2016.

30. Eadie LN, Dang P, Saunders VA, Yeung DT, Osborn MP, Grigg AP, Hughes TP and White DL: The clinical significance of ABCB1 overexpression in predicting outcome of CML patients undergoing first-line imatinib treatment. Leukemia 31: 75-82, 2017.

31. Silva KL, de Souza PS, Nestal de Moraes G, Moellmann-Coelho A, Vasconcelos Fda C and Maia RC: XIAP and P-glycoprotein co-expression is related to imatinib resistance in chronic myeloid leukemia cells. Leuk Res 37: 1350-1358, 2013.

32. Zhou SF: Structure, function and regulation of P-glycoprotein and its clinical relevance in drug disposition. Xenobiotica 38: 802-832, 2008

33. Thiebaut F, Tsuruo T, Hamada H, Gottesman MM, Pastan I and Willingham MC: Cellular localization of the multidrug-resistance gene product P-glycoprotein in normal human tissues. Proc Natl Acad Sci USA 84: 7735-7738, 1987.

34. Silva R, Vilas-Boas V, Carmo H, Dinis-Oliveira RJ, Carvalho F, de Lourdes Bastos M and Remião F: Modulation of P-glycoprotein efflux pump: Induction and activation as a therapeutic strategy. Pharmacol Ther 149: 1-123, 2015.

35. Fellner S, Bauer B, Miller DS, Schaffrik M, Fankhänel M, Spruss T, Bernhardt G, Graeff C, Färber L, Gschaidmeier H, et al: Transport of paclitaxel (Taxol) across the blood-brain barrier in vitro and in vivo. J Clin Invest 110: 1309-1318, 2002.

36. Inoue K: MicroRNA function in animal development. Tanpakushitsu Kakusan Koso 52: 197-204, 2007.

37. Williams AE, Moschos SA, Perry MM, Barnes PJ and Lindsay MA: Maternally imprinted microRNAs are differentially expressed during mouse and human lung development. Dev Dyn 236: 572-580, 2007.

38. Li X, Yu Z, Li Y, Liu S, Gao C, Hou X, Yao R and Cui L: The tumor suppressor miR-124 inhibits cell proliferation by targeting STAT3 and functions as a prognostic marker for postoperative NSCLC patients. Int J Oncol 46: 798-808, 2015. 
39. Lv ZC, Fan YS, Chen HB and Zhao DW: Investigation of microRNA-155 as a serum diagnostic and prognostic biomarker for colorectal cancer. Tumour Biol 36: 1619-1625, 2015.

40. Zhang KC, Xi HQ, Cui JX, Shen WS, Li JY, Wei B and Chen L: Hemolysis-free plasma miR-214 as novel biomarker of gastric cancer and is correlated with distant metastasis. Am J Cancer Res 5: 821-829, 2015.

41. Wang F, Lv P, Liu X, Zhu M and Qiu X: microRNA-214 enhances the invasion ability of breast cancer cells by targeting p53. Int J Mol Med 35: 1395-1402, 2015.

42. Wang J, Zhang X, Wang L, Yang Y, Dong Z, Wang H, Du L and Wang C: MicroRNA-214 suppresses oncogenesis and exerts impact on prognosis by targeting PDRG1 in bladder cancer. PLoS One 10: e0118086, 2015.
43. Wan DY, Zhang Z and Yang HH: Cardioprotective effect of miR-214 in myocardial ischemic postconditioning by down-regulation of hypoxia inducible factor 1 , alpha subunit inhibitor. Cell Mol Biol (Noisy-le-grand) 61: 1-6, 2015.

44. Izawa T, Horiuchi T, Atarashi M, Kuwamura M and Yamate J: Anti-fibrotic role of miR-214 in thioacetamide-induced liver cirrhosis in rats. Toxicol Pathol 43: 844-851, 2015.

This work is licensed under a Creative Commons Attribution-NonCommercial-NoDerivatives 4.0 International (CC BY-NC-ND 4.0) License. 